\title{
Structural and Phase Transformation in a Cold-Deformed Titanium Alloy During Aging
}

\section{A.G. Illarionov'1,2, I.V. Narygina1, M.S. Karabanalov¹, and I.A. Kylosova ${ }^{1}$}

${ }^{1}$ Federal State Autonomous Educational Institution of Higher Education «Ural Federal University named after the first President of Russia B.N.Yeltsin», Ekaterinburg, Russia

${ }^{2}$ M.N. Miheev Institute of Metal Physics of Ural Branch of Russian Academy of Sciences, $18 \mathrm{~S}$. Kovalevskaya Street, Yekaterinburg, Russia, 620137

\section{Abstract}

The change of structure, phase composition and properties during aging of VT22 (Ti-5Al-5Mo-5V-1Fe-1Cr) titanium alloy rods, pre-quenched from $\beta$ - or $(\alpha+\beta)$-region and cold deformed with different degrees of compression, were studied by such methods as SEM, XRD-analysis and microhardness measurement.

Keywords: titanium alloy, quenching, cold deformation, aging, phase transformation, structural transformation, microstructure, the morphology of phases, microhardness.

Corresponding Author:

A.G. Illarionov

a.g.illarionov@urfu.ru

Received: 25 February 2019

Accepted: 9 April 2019

Published: 15 April 2019

Publishing services provided by

Knowledge E

(c) A.G. Illarionov et al. This article is distributed under the terms of the Creative Commons

Attribution License, which

permits unrestricted use and

redistribution provided that the

original author and source are credited.

Selection and Peer-review under the responsibility of The Ural school-seminar of metal scientists-young researchers Conference Committee.

\section{Intorduction}

VT22 (Ti-5Al-5Mo-5V-1Fe-1Cr) high strength titanium alloy is promising for use in heavyduty structures of aerospace equipment such as the chassis, fuselage, wing of the aircraft, attaching parts such as power bolts due to high specific strength, viscosity, corrosion resistance, hardenability and high reliability during operation [1].

The effect of hardening during aging of $(\alpha+\beta)$-titanium alloys depends on both the product decomposition dispersion of the $\beta$-metastable solid solution and the product decomposition distribution in the structure.

The use of cold plastic deformation between quenching and aging will lead to the formation of dislocations and other deformation defects in the structure. It makes possible to modify the nucleation of the $\alpha$-phase during aging [2-6]. Thus, it allows improving the microstructure and increasing the complex of mechanical properties. In this regard, the aim of this research was to study the processes occurring during the aging of quenched and cold-deformed VT22 titanium alloy.

\section{G OPEN ACCESS}




\section{Research Material and Methods}

The material of the study was hot-rolled rods with a diameter of $15 \mathrm{~mm}$ made of industrial VT22 (Ti-5,52Al-4,94Mo-4,86V-1,11Fe-1,04Cr-0,110 (wt.\%) titanium alloy, manufactured at VSMPO-AVISMA Corporation.

First, cylindrical rods billet (diameter of $15 \mathrm{~mm}$ and height of $15 \mathrm{~mm}$ ) were heat treated in $\beta$-region at $950^{\circ} \mathrm{C}\left(\mathrm{T}_{\beta}+100{ }^{\circ} \mathrm{C}\right)$ or $(\alpha+\beta)$-region at $830^{\circ} \mathrm{C}\left(\mathrm{T}_{\beta}-30^{\circ} \mathrm{C}\right)$ for 1 hour and after quenched in water.

Then the quenched billets were cold deformed by compression along the rolling axis with different compression ratio $\varepsilon$. Deformation was performed on a hydraulic press with a force of $5 \mathrm{MN}$ using the graphite lubricant.

At the end, quenched and cold-deformed billets were aged at 500, 550, 600 or 650 ${ }^{\circ} \mathrm{C}$ for 4 hour.

The study was conducted using the methods of XRD-analysis on x-ray diffractometer Bruker D8 Advance; SEM using the microscope Jeol JSM-6490LV with the microanalysis system Oxford Instruments Inca Energy 350. Microhardness analysis was carried out on microscope Neophot-21 using consoles for the microhardness at a load of $100 \mathrm{~g}$.

\section{Results and Discussion}

According to the scanning electron microscopy decomposition of $\beta$-solid solution in quenched from $(\alpha+\beta)$-region alloy during aging occurs with the formation of a secondary $\alpha$-phase. Secondary $\alpha$-phase morphology represents plate packages of several orientations in the one $\beta$-grain (fig. 1, a-d). The interplate distance rises with the increase of aging temperature from 500 to $650{ }^{\circ} \mathrm{C}$ due to the acceleration of diffusion processes during the growth of temperature, noted in the works $[2,7,8]$.

The quenching from $\beta$-region compared to the quenching from $(\alpha+\beta)$-region leads to the formation of a more ordered "zigzag" structure in aging with a large average size of $\alpha$-plates (Fig. 2, a-d). This is due to the large recrystallized $\beta$-grain size.

By the method of XRD-analysis, it was found that an increase in the aging temperature from 500 to $650{ }^{\circ} \mathrm{C}$ firstly leads to a decrease in the $\alpha$-phase line physical broadening from 0,71 to 0,46 and from 0,80 to 0,47 for alloys quenched from $(\alpha+\beta)$ - and $\beta$-region respectively, secondly it leads to the ratio of the c/a crystal lattice parameter of $\alpha$-phase increase (Fig. 3, a) 


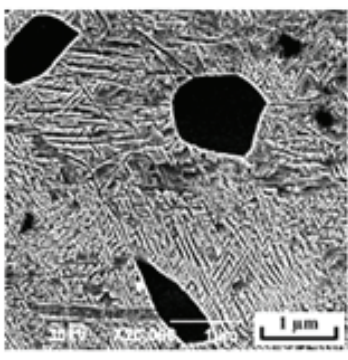

a

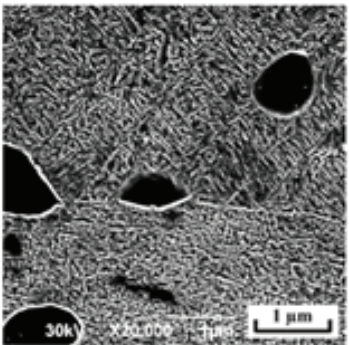

$\mathrm{e}$

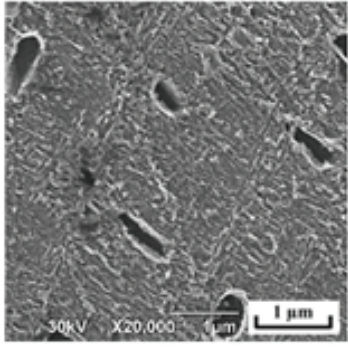

$\mathrm{i}$

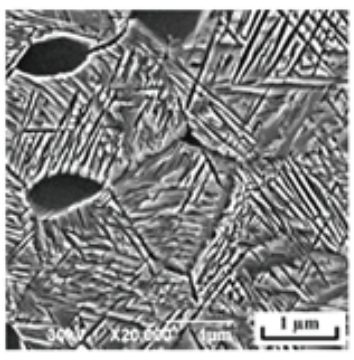

b

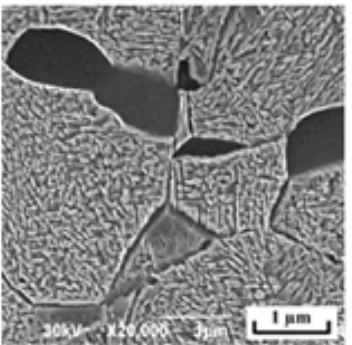

f

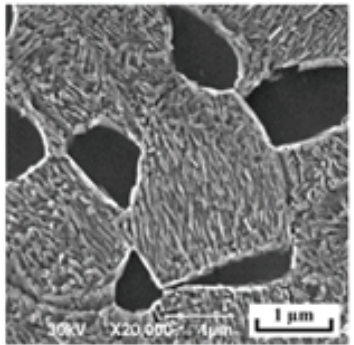

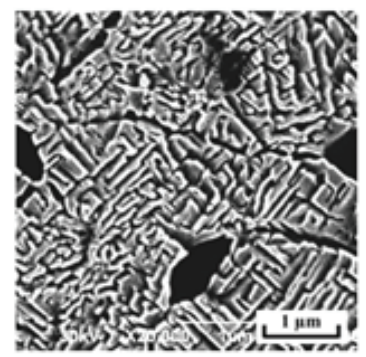

$\mathrm{c}$

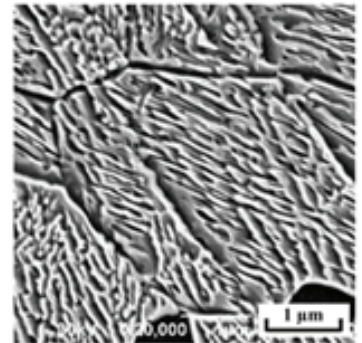

$\mathrm{g}$

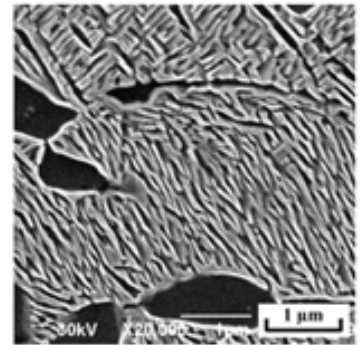

$\mathrm{k}$

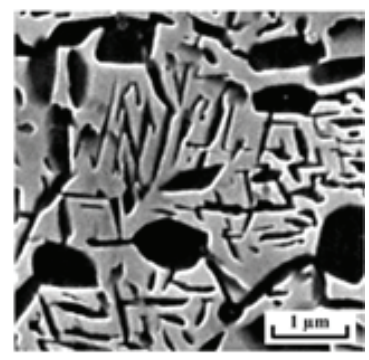

$\mathrm{d}$

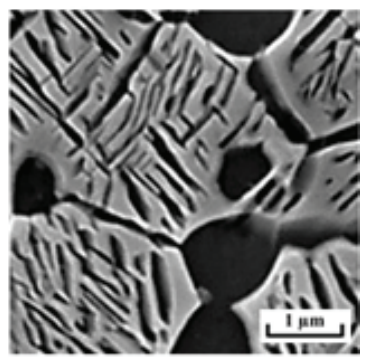

h

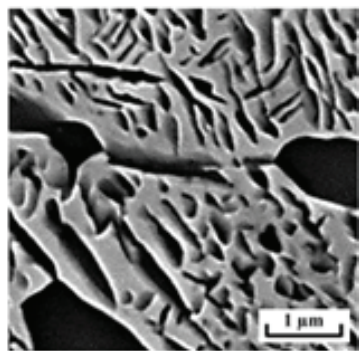

1

Figure 1: Microstructure of aged VT22 alloy, pre-quenched from $(\alpha+\beta)$-region at $830{ }^{\circ} \mathrm{C}$ and cold-deformed by compression: a-d - compression degree of $0 \%$; e-h - compression degree of $6 \%$; i-l - compression degree of $14 \%$; a, e, i - aging temperature of $500{ }^{\circ} \mathrm{C} ; \mathrm{b}, \mathrm{f}, \mathrm{j}$ - aging temperature of $550{ }^{\circ} \mathrm{C} ; \mathrm{c}, \mathrm{g}, \mathrm{k}$ - aging temperature of $600^{\circ} \mathrm{C} ; \mathrm{d}, \mathrm{h}, \mathrm{I}$ - aging temperature of $650^{\circ} \mathrm{C}$.

This indicates the formation of a less defective $\alpha$-phase with a high content of aluminum at higher temperature of aging, which is consistent with the data of [1, 2, 7-9].

The volume fraction of the secondary $\alpha$-phase decreases with the increase of the aging temperature, which leads to depletion of $\beta$-solid solution $\alpha$-stabilizing elements and the increase of the $\beta$-phase lattice period (Fig. 3, b).

The formation of larger $\alpha$-phase plates and the increase of $\beta$-solid solution volume fraction in the structure with the increase of aging temperature in alloys quenched both from $830^{\circ} \mathrm{C}$ and $950^{\circ} \mathrm{C}$, contributes to a decrease in microhardness from 5830 to 4370 $\mathrm{MPa}$ and from 5830 to $4580 \mathrm{MPa}$, respectively (Fig. 4). However, the overall level of microhardness of an alloy quenched from $950{ }^{\circ} \mathrm{C}$ is higher than of an alloy quenched from $830{ }^{\circ} \mathrm{C}$, due to the greater volume fraction of the secondary $\alpha$-precipitates during aging. 


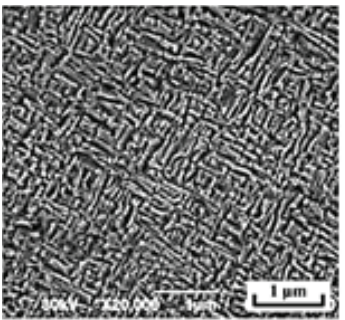

a

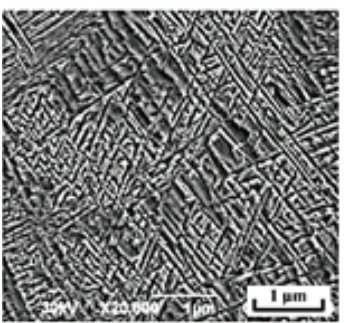

e

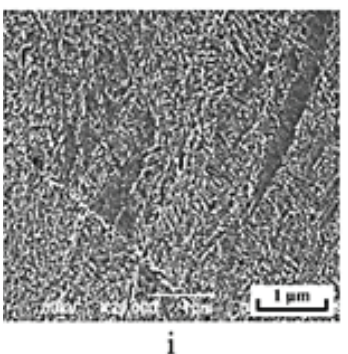

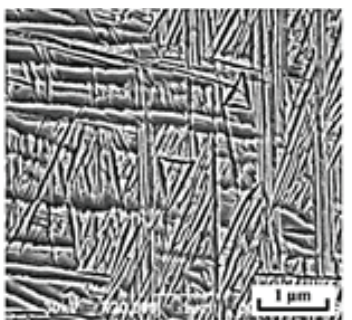

$\mathrm{b}$

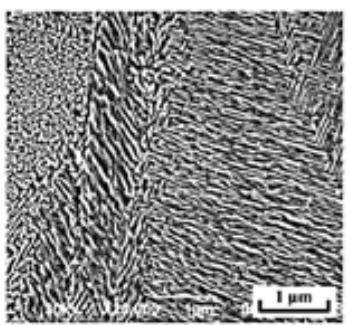

f

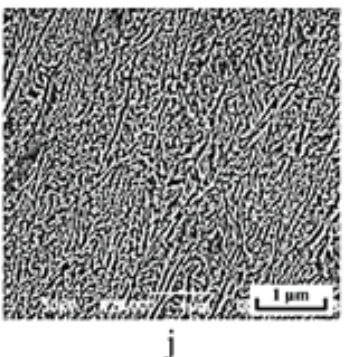

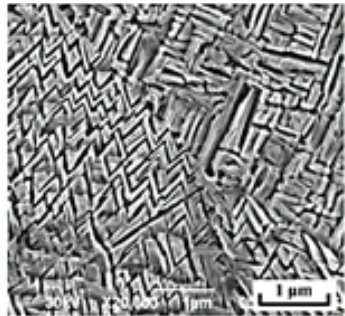

c

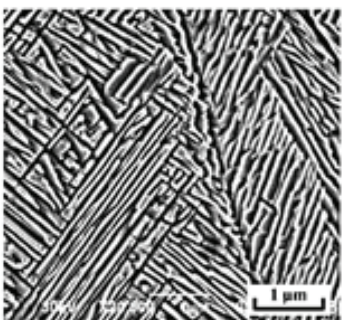

$\mathrm{g}$

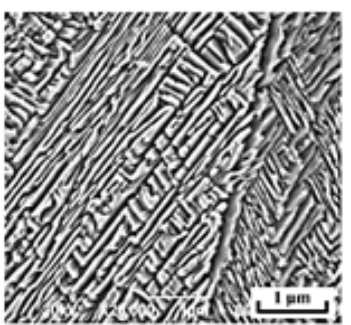

$\mathrm{k}$

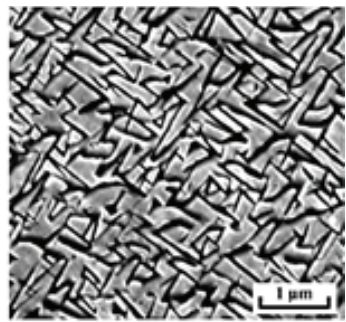

d

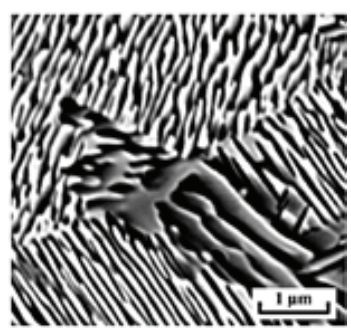

h

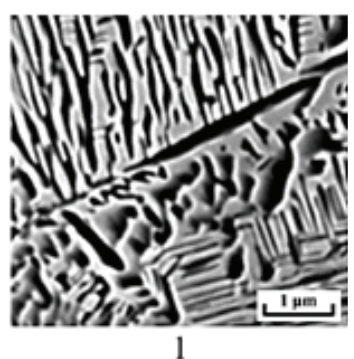

Figure 2: Microstructure of aged VT22 alloy, pre-quenched from $\beta$-region at $950{ }^{\circ} \mathrm{C}$ and cold-deformed by compression: a-d - compression degrees of $0 \%$; e-h - compression degree of $6 \%$; i- - - compression degree of $16 \%$; a, e, i - aging temperature of $500^{\circ} \mathrm{C} ; \mathrm{b}, \mathrm{f}, \mathrm{j}$ - aging temperature of $550^{\circ} \mathrm{C} ; \mathrm{c}, \mathrm{g}, \mathrm{k}$ - aging temperature of $600^{\circ} \mathrm{C} ; \mathrm{d}, \mathrm{h}, \mathrm{l}-$ aging temperature of $650^{\circ} \mathrm{C}$.

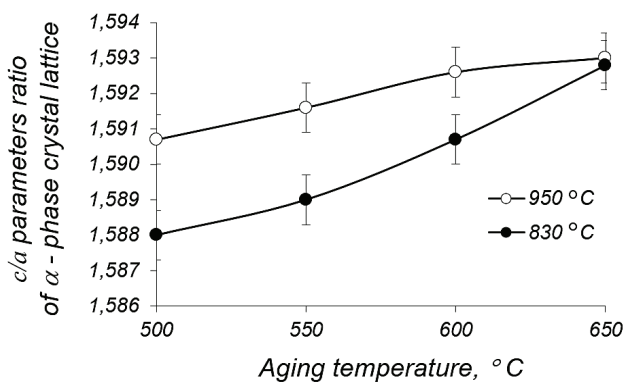

$\mathrm{a}$

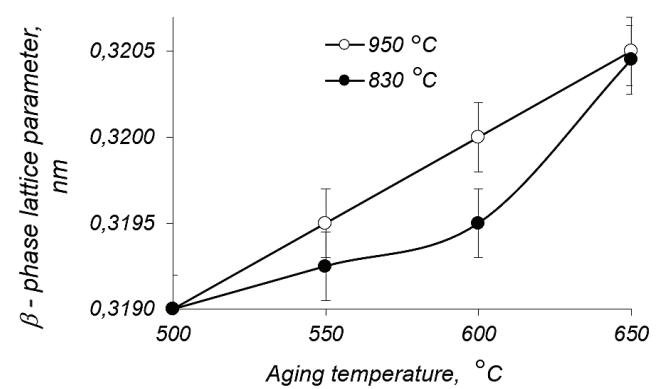

$\mathrm{b}$

Figure 3: $c / a$ parameters ratio of $\alpha$-phase crystal lattice and $\beta$-phase lattice parameter depending on the aging temperature of VT22 alloy at various quenching temperatures.

It was shown in previous work [10], that the phase and structural transformations of the alloy that take place during the cold deformation by compression are realized in the following sequence:

-structural transformations: easy (single) slip ( $\varepsilon \sim 2 \%$ ); multiple slip $(\varepsilon \sim 6 \%)$; the formation of a cellular structure $(\varepsilon \sim 16 \%)$; the formation of deformation twins $(\varepsilon \sim$ 


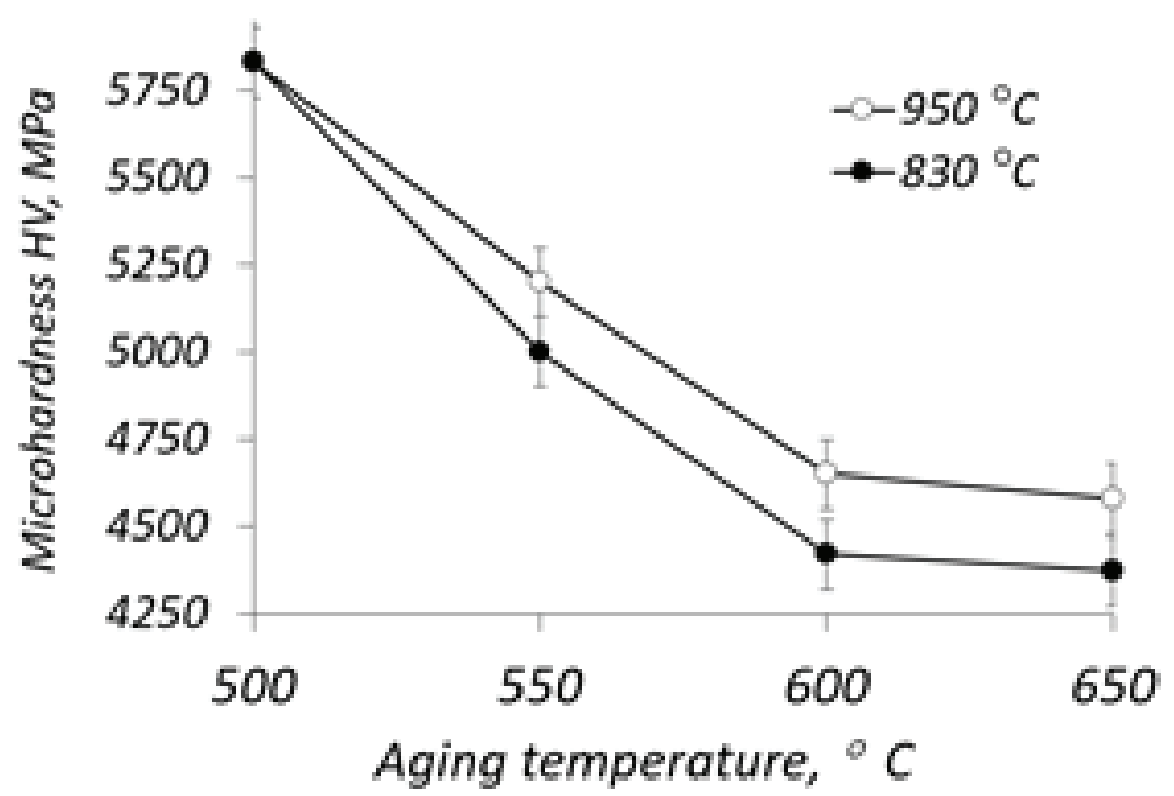

Figure 4: Microhardness of VT22 alloy depending on the aging temperature at various quenching temperatures.

$23 \%$ and greater). The formation of twins during deformation was also observed in the ordered $\beta$-matrix [11];

-phase transformations: the formation of the $\mathrm{T}$ phase at the degrees of deformation $6 \%$ and greater; the formation of $\alpha "$-martensite at the deformation degrees of $14-16 \%$ and greater. The phases of shear origin, i.e., the T phase and the $\alpha$ "-martensite, are similar. Such phases represent regions in the $\beta$-grains, which do not have clear interfaces with the matrix in the form of bands with an enhanced density of dislocations having characteristic orientations, which indicates that the $\alpha$ "-martensite may inherit its morphology from the $\mathrm{T}$ phase as a result of the $\mathrm{T}(\beta) \rightarrow \alpha$ " transformation.

Below we consider how this structure influence on the aging processes.

The morphology of the particle precipitation during the aging in the quenched from $\beta$ - and $(\alpha+\beta)$ - region of the alloy with cold plastic deformation of compression degrees up to $2 \%$ retained as in an undeformed state (Fig. 1, a-d and Fig. 2, a-d).

The rod compression degree of $6 \%$ and $14-16 \%$ leads to the decrease of $\alpha$-plates emerging during the aging (Fig. 1, e-I and Fig. 2, e-l). This is due to the rise of the crystalline structure defects density of $\beta$-solid solution, an increase in the length of the interphase boundaries during the formation of deformation-induced phases (T, $\alpha$ ") during the cold plastic deformation, thus, the rise of $\alpha$-phase origin places quantity. The precipitated plates are not always straight; often they are curved and have a wrong shape (Fig. 1, e-I and Fig. 2, e-I), moreover, the interplate distance at the coincided 
compression levels quenched alloys slightly rises during the increase of quenching temperature from 830 (Fig. 1, e-I) to $950^{\circ} \mathrm{C}$ (Fig. 2, e-I).

The growth of $c / a$ crystal lattice ratio of $\alpha$-phase saves during the rise of the aging temperature (Fig. 3, a) as well as after the cold plastic deformation (Fig. 5).

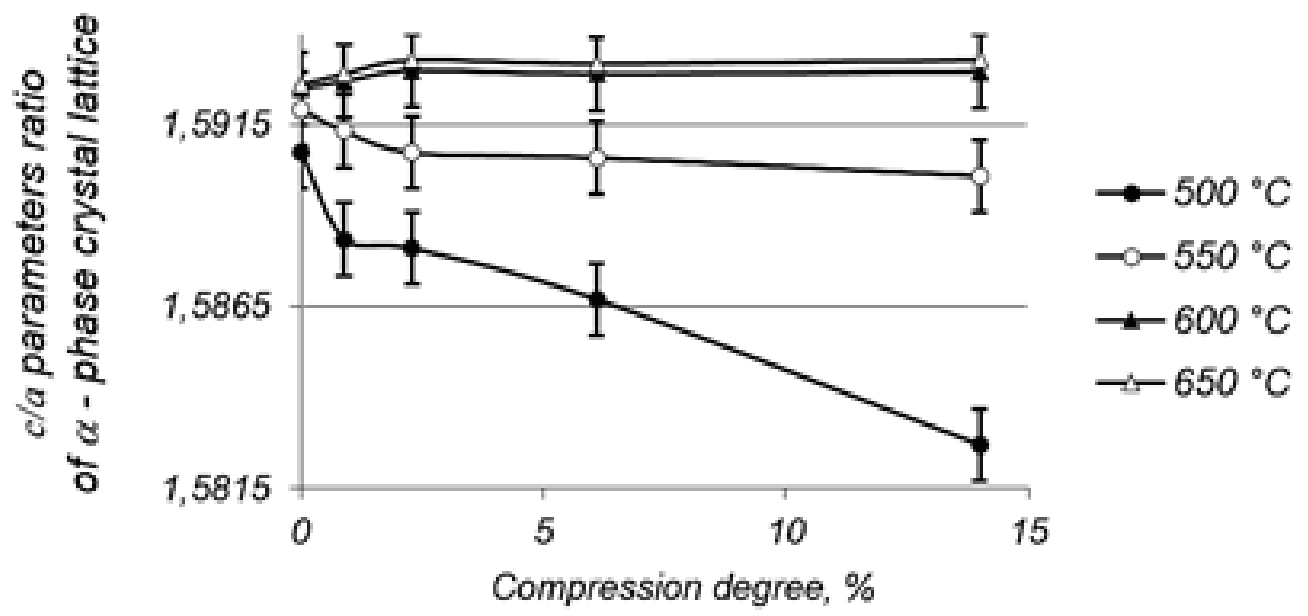

Figure 5: $c / a$ ratio of the $\alpha$-phase lattice after the aging at the different temperatures depending on the compression degree of rods quenched from $(\alpha+\beta)$-region.

The fixed level of $c / a$ steady changes depending on the deformation degree. It is related to the different completeness of $\beta$-solid solution decomposition and the deformation-induced phases formation.

Uptrend of $\beta$-phase crystal lattice periods of cold deformed rods with different compression degrees during the increase of the aging temperature saves as well as the described quenched and aged rods. This means that the 4-hour exposure chosen for aging ensures a sufficiently complete process of decomposition in both quenched and deformed alloys with the formation of the $(\alpha+\beta)$-structure with a close to equilibrium composition of the phases.

The microhardness behavior depends on the aging temperature and the quenching temperature depending on the compression degree (Fig. 6).

Some decrease of the durometric characteristics during the rise of the compression degree is related to the coagulation processes of precipitating $\alpha$-particles in a highdeformed alloys at the aging temperatures of $600^{\circ} \mathrm{C}$ and $650^{\circ} \mathrm{C}$. A softening due to the $\alpha$-particles coagulation is less significant because of lower temperature (at the aging temperature of $550 \%$. It is compensated by the $\beta$-matrix hardening due to previous cold plastic deformation. This causes the constant level of microhardness at the different compression degrees. During the aging at $500^{\circ} \mathrm{C}$ strength increases at low deformation degrees due to the $\beta$-matrix deformation hardening, and the yield on a constant level at higher degrees is due to the same reasons as during aging at $550^{\circ} \mathrm{C}$. The general level 


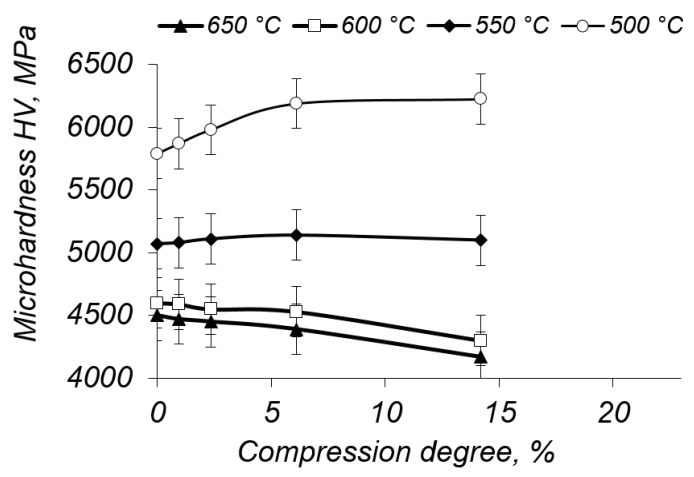

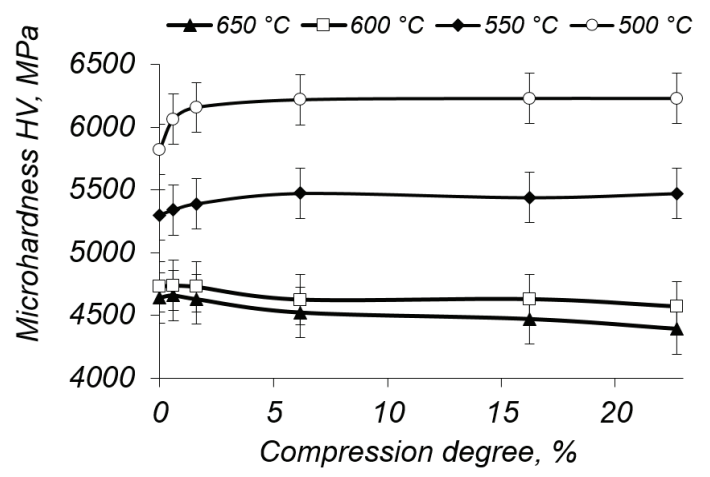

b

Figure 6: Microhardness after aging at the different temperatures depending on cold plastic deformation degrees of VT22 alloy, pre-quenched from temperatures of: $a-830^{\circ} \mathrm{C} ; \mathrm{b}-950^{\circ} \mathrm{C}$.

of the microhardness during the aging after quenching from $950^{\circ} \mathrm{C}$ is higher than after the quenching from $830^{\circ} \mathrm{C}$, due to the larger volume fraction of secondary $\alpha$-particles because of the absence of primary $\alpha$-particles.

\section{Conclusion}

Thus, it is shown that the increase in the quenching temperature of hot-rolled in $(\alpha+\beta)$ region rods of VT22 titanium alloy from $830^{\circ} \mathrm{C}$ to $950^{\circ} \mathrm{C}$ contributes to obtaining higher durometric characteristics of the quenched and cold-deformed alloys at the same aging temperatures due to the larger volume fraction of decomposition products.

The cold plastic deformation before the aging leads to the change of $\alpha$-precipitation morphology at the deformation degrees larger than $6 \%$. The behavior of durometric characteristics change with the deformation degree at the aging is determined by the development of the alloy softening processes, due to the development of coagulation processes of the second phase particles, and hardening as a result of deformation hardening and the intensification of the $\alpha$-particles precipitation.

The study was supported by the Ministry of Science and Higher Education of the Russian Federation No 11.8386.2017/8.9

The work was carried out using the laboratory equipment "Structural methods of analysis and properties of materials and nanomaterials" of the Center of Ural Federal University. 


\section{References}

[1] J.D. Cotton, R.D. Briggs, R.R. Boyer, N.V. Shchetnikov, J.C. Fanning, State of the Art in Beta Titanium Alloys for Airframe Applications, JOM. 67 (2015) 1281-1303.

[2] O.M. Ivasishin, P.E. Markovsky, Yu.V. Matviychuk, S.L. Semiatin, C.H. Ward, S. Fox, A comparative study of the mechanical properties of high-strength $\beta$-titanium alloys, J. of Alloys and Compounds. 457 (2008) 296-309.

[3] H. Ohyama, T. Nishimura, Y. Ashida, Effects of cold deformation on the morphology of $\alpha$ precipitates in $\beta$ titanium alloys, J. KOBELCO Technology Review. 17 (1994) 61-65.

[4] T. Furuhara, Role of defects on microstructure development of beta titanium alloys, J. Metals and Materials International. 6 (2000) 221-224.

[5] B. Zhang, T. Yang, M. Huang, D. Wang, Q. Sun, Y. Wang, J. Sun, Design of uniform nano $\alpha$ precipitates in a pre-deformed $\beta$-Ti alloy with high mechanical performance, J. of Materials Research and Technology (2018), article in press.

[6] S. Sadeghpour, S.M. Abbasi, M. Morakabati, L.P. Karjalainen, D.A. Porter, Effect of cold rolling and subsequent annealing on grain refinement of a beta titanium alloy showing stress-induced martensitic transformation, J. Materials Science and Engineering A. 731 (2018) 465-478.

[7] S.K. Kar, A. Ghosh, N. Fulzele, A. Bhattacharjee, Quantitative microstructural characterization of a near beta Ti alloy, Ti-5553 under different processing conditions, J. Materials Characterization. 81 (2013) 37-48.

[8] C. Leyens, M. Peters, Titanium and Titanium Alloys: Fundamentals and Applications. Wiley-VCH Verlag GmbH \& Co, 2003. 513 p.

[9] O.V. Abolikhina, S.L. Antonyuk, O.H. Molyar, Structure, strength and plasticity of semifinished products of VT22 titanium alloy, J. Materials Science. 3 (2008) 400404.

[10] A.G. Illarionov, I.V. Narygina, M.S. Karabanalov, A.A. Popov, O.A. Elkina, Structural and phase transformations in a titanium alloy of the transition class under the effect of deformation, J. Physics of Metals and Metallography. 110 (2010) 279-288.

[11] N.V. Kazantseva, S.L. Demakov, A.A. Popov, Microstructure and plastic deformation of orthorhombic titanium aluminides $\mathrm{Ti}_{2} \mathrm{AINb}$. III. Formation of transformation twins upon the $\mathrm{B}_{2} \rightarrow \mathrm{O}$ phase transformation, J. Physics of Metals and Metallography. 103 (2007) 378-387. 